\title{
Exchanges of water and certain water-soluble minerals during passage of digesta through the stomach compartments of young ruminating bovines
}

\author{
BY B. M. EDRISE*, R. H. SMITH† AND D. HEWITT \\ National Institute for Research in Dairying $\ddagger$, Shinfield, Reading, Berks RG2 9AT
}

(Received 25 October 1984 - Accepted 31 July 1985)

\begin{abstract}
1. Four ruminating bull calves were provided with cannulas in the rumen and abomasum and a sleeve sutured at the omosal-abomasal orifice that permitted digesta flowing from the omasum to be diverted and collected.

2. The calves were each given in turn a high-roughage (HR) and high-concentrate (HC) diet consisting mainly of dried grass and flaked maize in the proportions $3: 2$ and $1: 2$ by weight respectively. Water-soluble non-absorbable marker (polyethylene glycol) was also given and the diets were sometimes supplemented with magnesium sulphate. For each diet $(\mathrm{HR}(0), \mathrm{HR}(\mathrm{Mg}), \mathrm{HC}(0), \mathrm{HC}(\mathrm{Mg}))$, collections were made from the rumen, reticulum, omasal outflow and abomasum, and flows of water, sodium, potassium and chloride calculated at these sites relative to intakes.

3. The general pattern of net exchange was similar for all the diets. Substantial additions of water and $\mathrm{Na}$, a small addition of $\mathrm{K}$ and a small absorption of $\mathrm{Cl}$ occurred between mouth and reticulum. Substantial (approximately $40-60 \%$ ) absorption of water and $\mathrm{Na}$, a small absorption of $\mathrm{K}$ and considerable secretion of $\mathrm{Cl}$ occurred in the omasum. Quantitative comparisons indicated that addition of water and $\mathrm{Na}$ up to the reticulum, presumably in saliva, was significantly greater for the HR than the HC diets. Addition of $\mathrm{Mg}$ appeared to stimulate absorption of $\mathrm{Na}$ and water up to the reticulum for unknown reasons. Re-absorption of these components in the omasum varied for different calves and diets but appeared to be influenced primarily by a positive linear relation between amounts of digesta flowing into the omasum and amounts of water and Na absorbed from it. The proportion of water absorbed also increased with increasing entry rates of water.

4. Other findings showed that $\mathrm{pH}$ values rose slightly (about $0.2 \mathrm{pH}$ units) but significantly in the reticulum compared with the rumen and that the value fell again by about the same amount during the passage of digesta through the omasum. Changes between omasal outflow and the abomasum were as expected, with marked additions of $\mathrm{Cl}, \mathrm{Na}$ and water and a fall in $\mathrm{pH}$.
\end{abstract}

Although there is a considerable amount of information on exchanges of water and major minerals between mouth and duodenum of the ruminant and within the rumen (e.g. Bertoni et al. 1976), much less is known about the pattern of exchange as digesta move from one site within the stomach to another. These more detailed items of information are necessary to develop a fuller understanding of the homeostatic regulation of the different components, their economy of use and disorders resulting from deficient or unbalanced intakes. Apart from specific deficiencies which may affect microbial activity (Durand \& Kawashima, 1980) or the whole animal, disorders may also arise by an excess of one mineral ion depressing the uptake of another; there is, for example, evidence that excess potassium inhibits magnesium absorption in the stomach of the steer (Horn \& Smith, 1978). Changes between amounts of the major minerals and water consumed and flowing out of the reticulum are net effects of $(a)$ secretion of saliva and $(b)$ absorption and secretion in the reticulo-rumen.

Available evidence for cattle and sheep indicates that within the reticulo-rumen, sodium and chloride are actively absorbed while $\mathrm{K}$ more generally moves with the electrochemical gradient (Scott, 1967). It is probable that absorption of water generally occurs simply as a result of osmotic forces (Dobson et al. 1976). There is little published information on the

\footnotetext{
* Present address: Faculty of Veterinary Medicine, University of Cairo, Giza Square, Cairo, Egypt.

+ For reprints.

$\ddagger$ Now the Animal and Grassland Research Institute, Shinfield, Reading, Berks RG2 9AQ.
} 
combined effects of saliva secretion and reticulo-rumen exchanges for the bovine under different dietary conditions and one part of the present study was designed to investigate this.

Early ideas about water and mineral exchanges in the omasum were based, in the main, on the analyses of omasal contents from slaughtered animals. These observations led to the conclusion that extensive absorption of water and other constituents occurred at this site in sheep as well as cattle. However, as was pointed out by Englehardt \& Hauffe (1975), this technique greatly overestimates water uptake as it takes no account of different rates of flow of liquid and solid components of digesta through the omasum. Englehardt \& Hauffe (1975) showed from measurement of omasal outflow in the conscious sheep that, on average, only about $13 \%$ of the water entering the omasum was absorbed and there were only relatively small amounts of $\mathrm{Na}$ absorption and chloride secretion as digesta moved through the organ. A further objective of the present work was to extend such observations to the ruminating calf.

Finally, some information was sought on the change in digesta composition with movement from the omasum to the abomasum of the calf.

Preliminary reports of this work have appeared elsewhere (Edrise et al. 1977; Edrise \& Smith, 1979).

\section{EX PER IMENT AL}

\section{Animals and feeding}

Four Friesian bull calves (nos 1-4) were weaned by about 7 weeks of age and given a diet of hay and a normal calf-rearing concentrate mixture for a growth rate of about $0.4 \mathrm{~kg} / \mathrm{d}$ (Ministry of Agriculture, Fisheries and Food, 1975). At 120-146 d of age (96-117 kg live weight) each was provided with a rumen cannula of rubber with an internal diameter of $38 \mathrm{~mm}$ (Avon Rubber Co., Bradford-on-Avon, Wiltshire) as well as a cannula in the fundic region of the abomasum made of polyacetal (Kemetal; ICI, Plastic Division, Welwyn Garden City, Herts) with an internal diameter of $32 \mathrm{~mm}$ and a circular flange within the abomasum of about $80 \mathrm{~mm}$ diameter. The abomasal cannula was closed by inserting a closely fitting hollow rod sealed at the inner end which protruded about $20 \mathrm{~mm}$ into the abomasal cavity. At the same time that the abomasal cannula was installed, a flexible tube of reinforced silastic sheet $0.18 \mathrm{~mm}$ thick (catalogue no. 501-1, Dow Corning Corporation Medical Products, Midland, Michigan) was prepared, approximately $200 \mathrm{~mm}$ long and $50 \mathrm{~mm}$ diameter. One end was sutured, essentially according to the technique described for sheep and goats by Hauffe \& Englehardt (1975), at the omasal side of the omasal-abomasal orifice. The other end normally lay freely in the body of the abomasum. The sleeve could be exteriorized at the times of sampling by pulling the outside end through the abomasal cannula and the flow of digesta from the omasum collected directly.

Experimental collections were begun not less than 4 weeks after surgery and not less than 2 weeks after introducing the appropriate diet.

Four diets were given successively, consisting mainly of dried grass and flaked maize with different $\mathrm{Mg}$ supplements in the amounts shown in Table 1. Two calves were given high-roughage diets in the first and second periods and then low-roughage diets in the third and fourth periods while the other two calves received these diet types in the reverse order. Calf 4 did not receive the high-roughage diets due to cannula loss.

The first collections were made when the animals had received the appropriate diets supplemented with $\mathrm{Mg}$ for at least $15 \mathrm{~d}$. The $\mathrm{Mg}$ supplement was then removed and further collections made after $7 \mathrm{~d}$. After the change from low-to high-roughage diets or vice versa and resuming the $\mathrm{Mg}$ supplement the animals were kept on the new diet for $15 \mathrm{~d}$ before 
Table 1. Daily intakes $(\mathrm{kg})$ of feed components for high-roughage $(H R)$ or high-concentrate $(H C)$ diets with $(\mathrm{Mg})$ or without $(0)$ magnesium supplement. Vitamins $A, D$ and $E$ were also added

\begin{tabular}{lllll}
\hline \hline Diet $\ldots$ & HR(0) & HR(Mg) & HC(0) & HC(Mg) \\
\hline Dried grass & 1.20 & 1.20 & 0.68 & 0.68 \\
Flaked maize & 0.83 & 0.83 & 1.40 & 1.40 \\
$\mathrm{MgSO}_{4} \cdot 7 \mathrm{H}_{2} \mathrm{O}$ & 0 & 0.060 & 0 & 0.060 \\
$\mathrm{NaH}_{2} \mathrm{PO}_{4} \cdot 2 \mathrm{H}_{2} \mathrm{O}$ & 0.013 & 0.013 & 0.013 & 0.013 \\
$\mathrm{CaCl}_{2} \cdot 6 \mathrm{H}_{2} \mathrm{O}$ & 0.017 & 0.017 & 0.017 & 0.017 \\
\hline
\end{tabular}

the third set of collections was made. The $\mathrm{Mg}$ supplement was then removed once more and after $7 \mathrm{~d}$ the fourth collection was made. Meals were given in equal amounts twice a day at 09.00 and 17.00 hours. A water-soluble marker (polyethylene glycol (PEG), molecular weight 4000$)$ and a particulate marker $\left({ }^{103} \mathrm{Ru}\right.$, as phenanthroline complex, prepared by the procedure of Tan et al. (1971)) were added to the diets in amounts of $60 \mathrm{~g}$ and $0 \cdot 2-0.5 \mathrm{MBq} /$ feed respectively but only the water-soluble marker features in the present experiments.

For an experimental collection, samples were taken from the rumen, reticulum, omasal outflow and abomasum just before and at 2 and $5 \mathrm{~h}$ after a normal feed. A rumen sample $(200-250 \mathrm{~g})$ was collected from different locations in the organ using a rigid tube at the end of which was a stainless-steel sieve in the form of a capsule $(55 \mathrm{~mm}$ long and $14 \mathrm{~mm}$ internal diameter with $1.07 \mathrm{~mm}$ diameter holes). A reticulum sample (200-250 g) was obtained by inserting a curved tube, ending with a similar capsule, into the reticulum taking the anterior rumen pillar as a guide and crossing over the reticulo-ruminal fold. For a particular diet and animal, this method of collection consistently gave rumen samples of similar composition with respect to dry matter content. They were nearly always different in composition from reticulum samples as indicated by the mean values in Fig. 1, but differences were always small and usually consistent in direction, giving an indication that sampling was carried out in a reasonably reproducible way at these sites throughout the experimental periods.

Abomasal digesta samples were collected by simply opening the abomasal cannula. After collecting the required amount (about $150-180 \mathrm{~g}$ ) of abomasal contents, the omasal sleeve was pulled out and the omasal outflow of digesta collected. The time taken for collecting an appropriate amount (200-220 g) of the omasal outflow (approximately five to eight gushes) was recorded for three of the calves (nos 2, 3,4) and the values used to make a direct estimate of the omasal outflow rate. It was observed that the omasal outflow samples came in two different alternating gushes. In the first gush a smaller volume of digesta containing less solid material appeared than in the second gush. The time intervals between gushes varied from 3 to $7 \mathrm{~min}$ in the different calves.

All samples were transferred to the laboratory within $15 \mathrm{~min}$ of collection. Samples for $\mathrm{pH}$ determination were kept undisturbed and measurement made immediately. Samples for analysis were homogenized for $3 \mathrm{~min}$ (Atomix homogenizer; MSE Ltd, London). About $100 \mathrm{~g}$ of each of the homogenates were centrifuged for $30 \mathrm{~min}$ at $36000 \mathrm{~g}$. The clear supernatant fraction was stored at $-20^{\circ}$ until it was analysed.

For calves 1 and 2, several observations were made for each diet at 2-d intervals during collection periods up to $8 \mathrm{~d}$, but for the results given in the present paper single overall means for each calf were used. 


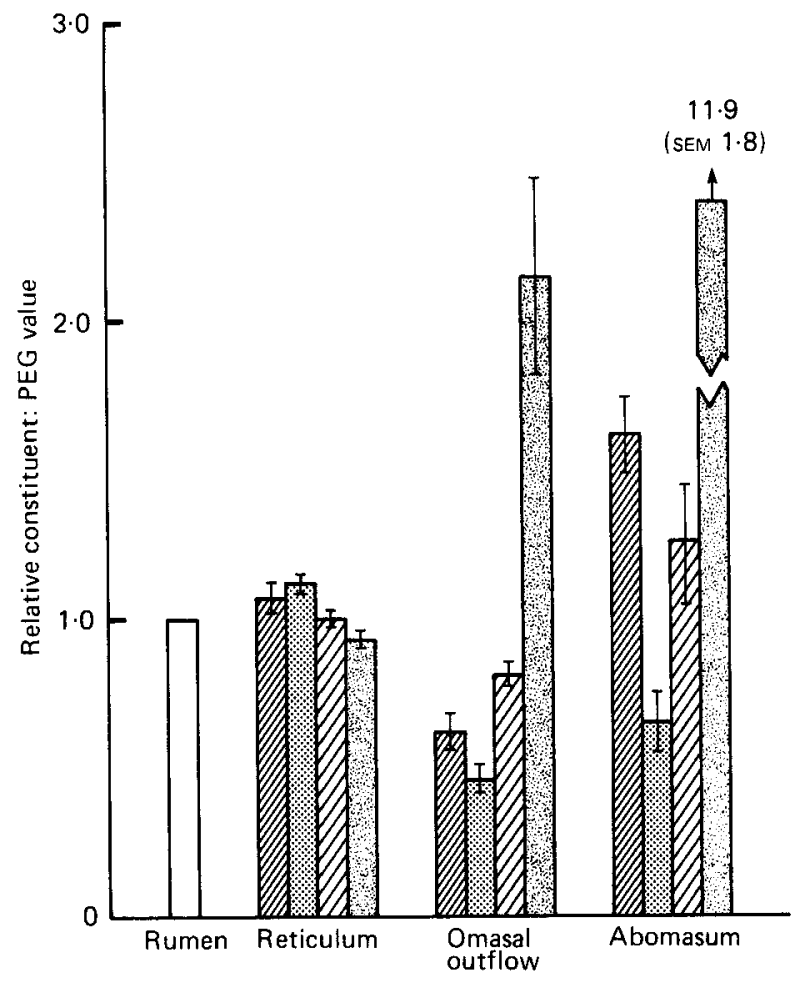

Fig. 1. Relative ratios of water $(\mathbb{Z})$, $\mathrm{Na}(\mathrm{O}), \mathrm{K}(\mathrm{Q})$ and $\mathrm{Cl}(\mathrm{\nabla})$ ) to the non-absorbable marker polyethylene glycol in samples taken from different sites in the stomach of ruminating calves $2 \mathrm{~h}$ after feeding. A value of 1.0 was assigned to the ratios in rumen contents. Results were mean values ( $2 \mathrm{df}$ ) for three calves given the high-roughage diet not supplemented with magnesium (see Table 1), with standard errors represented by vertical bars.

\section{Chemical analysis}

$\mathrm{Na}$ and $\mathrm{K}$ were determined in samples of digesta supernatant, suitably diluted with deionized water, by flame emission spectroscopy. $\mathrm{Cl}$ was determined using an EEL chloride meter (Evans Electroselenium Ltd, Halstead, Essex). Analyses in feed components were carried out similarly on supernatant fractions obtained after homogenizing with deionized water. Preliminary experiments showed that at least $95 \%$ of these components were recovered in this way. Dry matter contents of feed and digesta samples were determined using 5-15 g samples and drying to constant weight at 101-105 $5^{\circ}$ PEG was determined in digesta by the method described by Smith (1958) except that a period of 20 min was allowed for the development of turbidity.

\section{Statistical analysis}

The results used to prepare Table 3 (p. 162) came from a cross-over design (see p. 158); half of the calves received the two high-roughage diets followed by the two low-roughage diets, half low- followed by high-roughage diets. As the minerals examined were at least $95 \%$ soluble all flows were calculated on the basis of PEG as marker. There was no evidence of an effect of time; mean values for the first half of the experiment differed little from those for the second half, though with only 1 error degree of freedom this could not be established statistically and it should be noted that any time effect would be confounded with the $\mathrm{Mg}$ effect. The data for the four diets, high-roughage and high-concentrate with and without 
Table 2. Concentrations ( $\mathrm{mmol} / \mathrm{l}$ ) of sodium, potassium and chloride in rumen samples taken before and at different times after giving the high-roughage diet without magnesium supplement (see Table 1)

(Mean values with their standard errors for three calves)

\begin{tabular}{|c|c|c|c|c|c|c|}
\hline \multirow{2}{*}{$\begin{array}{l}\text { Period after feeding (h) ... } \\
\text { Concentration (mmol/l) }\end{array}$} & \multicolumn{2}{|c|}{0} & \multicolumn{2}{|c|}{2} & \multicolumn{2}{|c|}{5} \\
\hline & Mean & SEM & Mean & SEM & Mean & SEM \\
\hline $\mathrm{Na}$ & 113 & $7 \cdot 4$ & 102 & 7.9 & 106 & 6.4 \\
\hline $\mathrm{K}$ & $34 \cdot 3$ & 6.7 & $36 \cdot 5$ & 8.7 & $33 \cdot 5$ & 8.6 \\
\hline $\mathrm{Cl}$ & $8 \cdot 2$ & $1 \cdot 1$ & $13 \cdot 0$ & $2 \cdot 1$ & $10 \cdot 4$ & 1.6 \\
\hline
\end{tabular}

a $\mathrm{Mg}$ supplement, were subjected to a standard analysis of variance for randomized block experiments with calves as blocks. In addition, linear regression equations were calculated relating exchanges of water, $\mathrm{Na}, \mathrm{K}$ or $\mathrm{Cl}$ between the reticulo-omasal and omasal-abomasal orifices to flow of water at the reticulo-omasal orifice.

\section{RESULTS}

Samples of rumen, reticulum, omasal outflow and abomasal contents for any one calf on a particular diet were taken before a morning feed and at 2 and $5 \mathrm{~h}$ after the feed and analysed separately.

At the rumen it was found for all diets that, on average, there were small and non-significant falls in $\mathrm{Na}$ concentration and increases in $\mathrm{K}$ concentration. There were larger but non-significant rises in $\mathrm{Cl}$ concentration between the prefeed samples and the $2 \mathrm{~h}$ samples but a return to near the prefeed value by $5 \mathrm{~h}$ after feeding. Examples for the $\operatorname{HR}(0)$ diet are shown in Table 2.

These diurnal changes clearly affected the compositions of samples from other sites in the stomach but changes as digesta moved through the different stomach compartments are best represented in relation to the non-absorbable water-soluble marker PEG. As typical examples, for reticulum digesta samples from experiments in which calf 2 was given diet HR(0), constituent: PEG values $(\mathrm{mmol} / \mathrm{g})$ at 0,2 and $5 \mathrm{~h}$ after feeding were respectively $21.9,15.8$ and 17.2 for Na:PEG; 5.96, 4.93 and 4.98 for $\mathrm{K}: \mathrm{PEG}$ and $1.77,2.30$ and 1.90 for $\mathrm{Cl}$ :PEG. No appreciably greater variability was seen for other sites, calves or diets. Thus patterns of change for any one of these constituents between sites up to the abomasum, were closely similar whichever sampling time was used. There was also little difference in the patterns for the different diets. As an illustration of this pattern, mean values for constituent:PEG values relative to an assigned value of 1.0 for the rumen are shown in Fig. 1 for $2 \mathrm{~h}$ samples from calves $1-3$ receiving the $H R(0)$ diet.

In order to estimate daily flows of constituents at the reticulum and out of the omasum, single mean values for each calf based on prefeed and 2 and $5 \mathrm{~h}$ postfeed samples for constituent:PEG values were used. Flows, shown in Table 3, were calculated by multiplying these mean values, expressed in appropriate units, by the daily intake of PEG. The assumption that these mean values were representative of the ratios in the total daily flows was considered a reasonable one because the variations in ratios between the different sampling times were very small in relation to differences between sampling sites. Evidence that marker flow rate during the sampling periods was reasonably representative of that over the $24 \mathrm{~h}$ period was provided by observations on those calves (nos 2,3 and 4 ) in which 


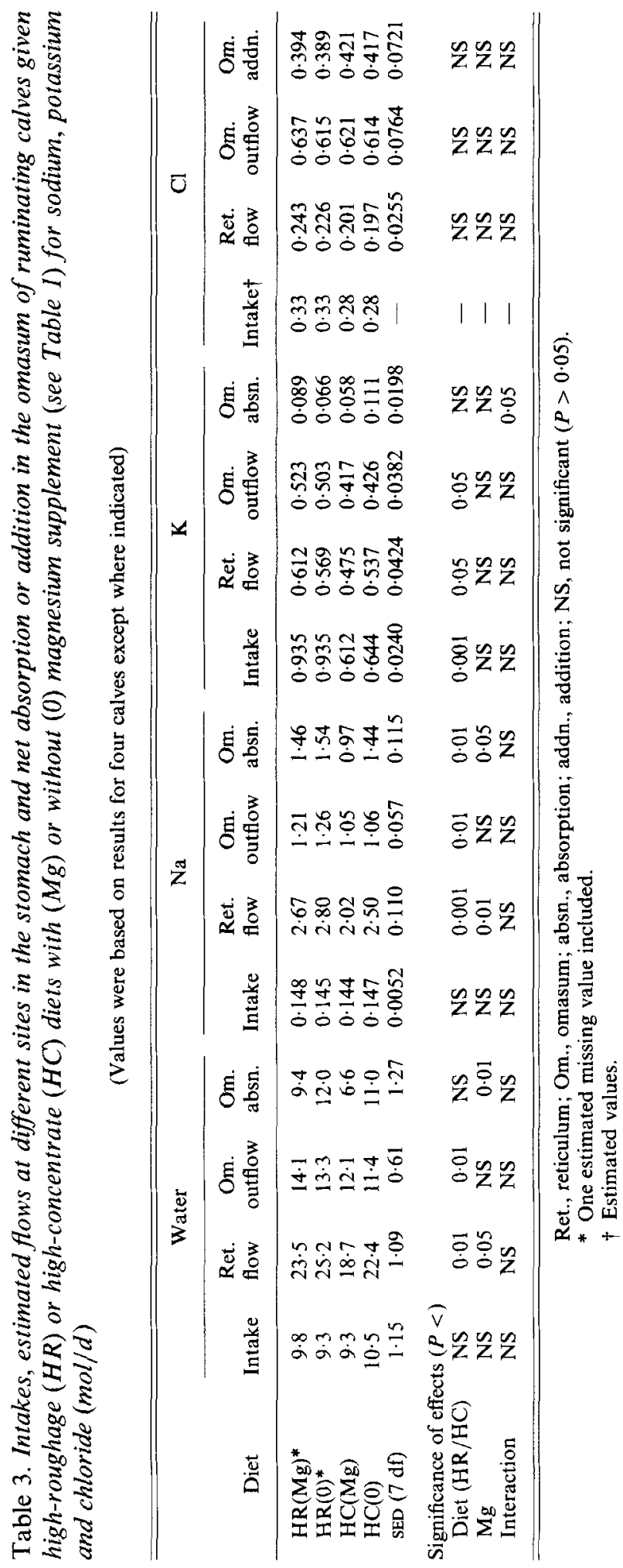



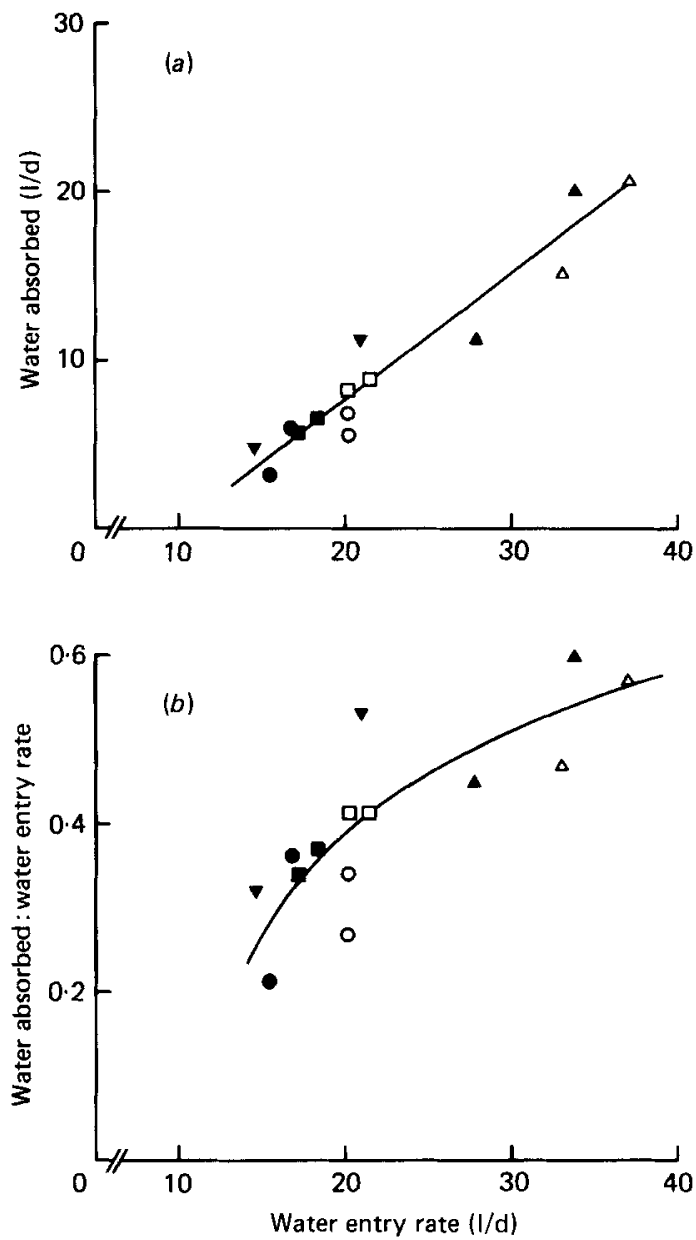

Fig. 2. Correlations between $(a)$ amounts and $(b)$ proportions of water absorbed in the omasum and the flow rate of water into the organ. Results are shown for calf $1: \triangle, \Delta$; calf $2: 0,0$; calf $3: \square, \square$; calf 4: $\boldsymbol{\nabla}$. High-roughage $(\triangle, \bigcirc, \square)$ or high-concentrate $(\boldsymbol{\Delta}, \boldsymbol{Q}, \boldsymbol{\square}, \boldsymbol{\nabla})$ diets were given (see Table 1$)$. No distinction is made between different magnesium intakes. The line shown in $(a)$ represents the linear regression equation in Table 4 (see p. 164) and that in $(b)$ is derived from it.

omasal digesta flow rates were measured directly during sampling. For ten experiments with these three calves, in which each diet was given at least twice, the mean recovery of the PEG dose over $24 \mathrm{~h}$ estimated from directly measured rates of outflow of omasal digesta and PEG concentrations in appropriate samples of that digesta was 0.95 (SEM 0.004). Although this value was less than $1 \cdot 0$ there were no significant differences between diets. Thus although the absolute values given in Table 3 may have shown small errors there seems good reason to suppose that they were valid for making comparisons between diets.

The values in Table 3 show that for all the diets there was a substantial net addition of endogenously derived water up to the reticulum outflow but this was significantly greater for the HR diets than for the corresponding HC diets. There was also a small but significant reduction in net endogenous water addition when $\mathrm{Mg}$ was added to the diet. Considerable amounts of water (on average $43 \%$ of that entering the organ with the digesta flow) were reabsorbed in the omasum but there was considerable variation between individual 
Table 4. Relation between water flow at the reticulum $(\mathrm{x})$ and amounts of different constituents absorbed or added in the omasum ( $\mathrm{y}$ )

(Linear regression equation $y=a+b x$ )

\begin{tabular}{lccc}
\hline \multicolumn{1}{c}{$\begin{array}{c}\text { (absolute quantities) } \\
\text { Water absorbed (l/d) }\end{array}$} & $a$ & $b$ & SE of $b(12 \mathrm{df})$ \\
\hline Sodium absorbed (mol/d) & -7.38 & $0.758^{* * *}$ & 0.0580 \\
Potassium absorbed (mol/d) & -0.037 & $0.0605^{* * *}$ & 0.00821 \\
Chloride added (mol/d) & 0.077 & $0.00011^{\text {NS }}$ & 0.00132 \\
& 0.061 & $0.0159^{* *}$ & 0.00380 \\
\hline
\end{tabular}

NS, not significant $(P>0.05)$.

** $P<0.01 ; \quad * * * P<0.001$.

Table 5. Changes with period after feeding in $p H$ values of digesta from different sites in the stomach of calves given high-roughage $(H R)$ or high-concentrate $(H C)$ diets without $(0)$ magnesium supplement (see Table 1)

(Mean values with their standard errors for three calves receiving diet $H R(0)$ and for four calves receiving diet $\mathrm{HC}(0))$

\begin{tabular}{|c|c|c|c|c|c|c|}
\hline \multirow{2}{*}{$\begin{array}{c}\text { Diet } \ldots \\
\text { Period after feeding }(\mathrm{h}) \ldots\end{array}$} & \multicolumn{3}{|c|}{$\mathrm{HR}(0)$} & \multicolumn{3}{|c|}{$\mathrm{HC}(0)$} \\
\hline & 0 & 2 & 5 & 0 & 2 & 5 \\
\hline \multicolumn{7}{|l|}{ Rumen } \\
\hline Mean & $7 \cdot 23$ & $6 \cdot 53$ & $6 \cdot 81$ & $7 \cdot 13$ & $6 \cdot 43$ & 6.67 \\
\hline SEM & 0.07 & $0 \cdot 09$ & 0.03 & 0.15 & 0.09 & 0.07 \\
\hline \multicolumn{7}{|l|}{ Reticulum } \\
\hline Mean & $7 \cdot 40$ & $6 \cdot 89$ & $7 \cdot 11$ & $7 \cdot 35$ & $6 \cdot 88$ & 6.98 \\
\hline SEM & 0.05 & $0 \cdot 02$ & 0.01 & $0 \cdot 14$ & 0.02 & $0 \cdot 15$ \\
\hline \multicolumn{7}{|l|}{ Omasal outflow } \\
\hline Mean & $7 \cdot 13$ & 6.65 & 6.90 & 6.98 & 6.41 & 6.63 \\
\hline SEM & 0.03 & 0.09 & 0.08 & 0.09 & $0 \cdot 11$ & 0.11 \\
\hline \multicolumn{7}{|l|}{ Abomasum } \\
\hline Mean & $3 \cdot 10$ & $3 \cdot 26$ & $2 \cdot 80$ & $3 \cdot 34$ & $2 \cdot 55$ & $3 \cdot 50$ \\
\hline SEM & $0 \cdot 30$ & 0.59 & 0.34 & 0.40 & 0.21 & 0.75 \\
\hline
\end{tabular}

experiments. It was apparent when all the calf results were examined together (similar trends were apparent in results for individual calves but these could not be compared with confidence because of the small numbers of observations) that there was a strong and highly significant correlation between amounts of water absorbed and the flow rate of water entering the omasum (Fig. 2(a)); the appropriate regression equation is shown in Table 4. This equation also implies an increase in the proportion of water absorbed with increase in flow rate as indicated in Fig. 2(b). It was apparent that on average, calf 1 absorbed a greater proportion of water entering the omasum than the other calves but it appears that this was because it also showed a greater flow of water into the omasum.

With the present diets nearly all the $\mathrm{Na}$ flowing from the reticulum to the omasum was endogenous in origin and presumably was derived mainly from saliva. Significantly greater amounts flowed at this site when $\mathrm{HR}$ rather than $\mathrm{HC}$ diets were given. A considerable amount of the $\mathrm{Na}$ (on average $54 \%$ of that entering the omasum with the digesta flow, see Table 3) was re-absorbed during passage through the omasum. In individual experiments, 
amounts absorbed showed a positive linear relation to the rate of flow of digesta into the omasum (Table 4) but for $\mathrm{Na}$, unlike for water, the proportion absorbed did not appear to differ with the flow rate.

The HR diets provided appreciably more $\mathrm{K}$ than the $\mathrm{HC}$ diets. For all the diets there was appreciable net disappearance of $\mathrm{K}$ between mouth and reticulum (on average $28 \%$ ) and, although the proportion absorbed tended to be higher for the higher intakes, flows at the reticulum reflected the differences in intakes.

Net absorption of $\mathrm{K}$ during passage of digesta through the omasum was low (on average $15 \%$ of that entering the omasum with the digesta flow, see Table 3 ) and showed no significant correlation with flow rate or any other property examined.

Because of an error in analysis, accurate intakes of $\mathrm{Cl}$ with the diet were unknown. From assumptions based on analyses of other maize and grass samples the values shown in Table 3 appear reasonable. These indicate a small net absorption between mouth and reticulum but this must be uncertain.

There was considerable net addition of $\mathrm{Cl}$ in the omasum, on average approximately twice the amounts entering (Table 3 ) with a strong positive correlation between amounts added and flow rate of digesta into the omasum (Table 4).

The results for samples of abomasal digesta given in Fig. 1 indicated that, as a net effect, very large amounts of $\mathrm{Cl}$, considerable amounts of water and smaller amounts of $\mathrm{Na}$ and $\mathrm{K}$ were added to digesta entering the abomasum. It is difficult to define these effects in precise quantitative terms because of the uncertainty about the extent to which omasal effluent was adequately mixed with abomasal secretions and how representative were samples taken from the site of the abomasal cannula (fundic region) of abomasal digesta in general.

Measurements of $\mathrm{pH}$ in the different samples after the $\mathrm{HR}(0)$ and $\mathrm{HC}(0)$ diets are shown in Table 5. Diurnal changes in the rumen were broadly as expected and were reflected at the other sites up to the omasal outflow. There was only a small difference apparent between the diets, and the $\mathrm{Mg}$ supplement (values not shown) had no effect. Samples from the rumen showed consistently lower values than those from the reticulum but differences were small. There was a consistent fall in $\mathrm{pH}$ during passage through the omasum but again differences were small.

\section{DISCUSSION}

The information obtained in the present work does not permit separation of effects due on the one hand to saliva secretion and, on the other, to exchanges across the wall of the reticulo-rumen. However, although detailed comparisons are impossible because of calf and diet differences, it may be calculated by scaling from the results of Yarns et al. (1965) on saliva production rates in young steers with oesophageal fistulas, that, for the present calves and diets, average saliva flow would have been about 22 litres/d. This is markedly greater than the observed net addition of water between mouth and reticulum even for the HR calves, implying substantial net absorption of water in the reticulo-rumen, most likely as a result of passive movement following exchanges of osmotically active solutes (Dobson et al. 1976). Nevertheless, it is probable that the greater water flow at the reticulum for the HR compared with the HC diets indicated greater saliva production for the former. This is not surprising; it is well-known that roughages increase rumination and this, in turn, increases saliva secretion (Brüggemann et al. 1965). The effect of dietary supplementation with $\mathrm{MgSO}_{4}$ in significantly reducing flow rate of water at the reticulum was, however, unexpected. It might be supposed that the effect of a $\mathrm{Mg}$ supplement would be to increase the osmotic pressure in the reticulo-rumen and therefore to favour movement of water into that organ but it is possible that the effect was mediated by an effect upon the uptake of other osmotically active digesta components such as $\mathrm{Na}$ (see p. 166). 
The finding that net absorption of water in the omasum as a proportion of that flowing into it was markedly greater in the calf than has been reported for the sheep and goat (Oyaert \& Bouchaert, 1961; Engelhardt \& Hauffe, 1975) presumably reflected the relatively greater size and complexity of the omasum in the bovine compared with the ovine (Edrise, 1979; Smith, 1984). As for the sheep (Engelhardt \& Hauffe, 1975), but at the higher level, absolute amounts of water absorbed in the calf omasum were related positively to amounts flowing into the organ (Fig. 2; Table 4) and this appeared to account for much of the animal-to-animal variation observed. The observation that the proportion of water absorbed in the omasum increased with increasing inflow implies the possibility of a regulatory process tending to maintain a reasonably constant omasal outflow. The mechanism is unknown but may have been related to differences in penetration of digesta within the omasal leaves. This is the result of a very complicated process (e.g. Sellers \& Stevens, 1966) with an outcome, in terms of efficiency, that is difficult to predict. The present finding of different alternating gushes of digesta from the omasum was in agreement with earlier observations (e.g. Ash, 1962) and was presumably a manifestation of such integrated activity.

Whatever the determining factors and detailed mechanisms, it was apparent that, for the conditions of the present experiments, the amount of water re-absorbed from the omasum formed a substantial part (roughly one half) of that added in the saliva. Thus, in the calf, it appears that the omasum helps to counteract the very great drain on body water imposed by high saliva production as well as preventing unnecessary dilution of gastric juice. Although absolute values for exchanges in the abomasum can be regarded only as approximations, the results indicated that the volume of gastric juice secreted was substantial and approximately equal to the volume of water absorbed in the omasum. This is consistent with earlier reports (Yang \& Thomas, 1965).

The secretory and absorptive processes determining the movements of minerals between the mouth and the reticulum outflow have been extensively studied (e.g. Kay, 1960; Sellers \& Dobson, 1960; Ferreira et al. 1972; Scott, 1975). The present work showed that the most substantial change resulting from the net effect of these processes under the conditions used was a massive movement of $\mathrm{Na}$ from the body to the digesta due primarily to secretion in saliva which was only partially counteracted by re-absorption in the reticulo-rumen. The significantly greater net secretion for the HR compared with the HC diet was presumably due, in the main, to a greater stimulation of total saliva flow for the former diet and this was reflected also in significantly greater net secretion of water and $\mathrm{K}$ and a (non-significant) greater net secretion of $\mathrm{Cl}$. The significant decrease in net $\mathrm{Na}$ (and water) secretion with $\mathrm{Mg}$ supplementation may also have been mediated by changes in saliva flow (although $\mathrm{K}$ and $\mathrm{Cl}$ were not consistently affected) but it is known that $\mathrm{K}$ supplementation stimulates $\mathrm{Na}$ absorption from the reticulo-rumen (Scott, 1975) and it is possible that $\mathrm{Mg}$ supplementation would have had a similiar effect.

The strong positive correlation between digesta flow rate into and amounts of $\mathrm{Na}$ absorbed from the omasum (Table 4) appeared to account for much of the significant difference between the HR-and $\mathrm{HC}$-fed calves in the amounts of $\mathrm{Na}$ re-absorbed in the omasum. On average, rather more than half the Na flowing out of the reticulo-rumen was absorbed as a net effect in the omasum; a considerably greater proportion than that reported for sheep or goats (Engelhardt \& Hauffe, 1975).

The relatively small difference observed between $\mathrm{K}$ intake and flow at the reticulum was consistent with earlier observations but whether net secretion or absorption of $\mathrm{K}$ would occur between these sites would probably depend upon level of intake. There was also relatively little net exchange of $\mathrm{K}$ in the omasum (absorption) or in the abomasum (secretion). This meant marked switches in the $\mathrm{Na}: \mathrm{K}$ value as digesta passed through the stomach compartments with a particularly low $\mathrm{Na}: \mathrm{K}$ value in the omasum. The possible 
effects of such differences upon the electrical potential across the tract wall and upon movements of other electrolytes such as $\mathrm{Mg}$ (Edrise \& Smith, 1979) should be kept in mind.

If it is assumed that, for the calves used in the present study, on average 22 litres saliva were produced daily (Yarns et al. 1965) containing about $11 \mathrm{mmol} \mathrm{Cl} / 1$ (Kay, 1960) it can be calculated that about $0.25 \mathrm{~mol} \mathrm{Cl} / \mathrm{d}$ would have been added endogenously to the reticulo-rumen. This, together with the probable dietary intake, (about $0.3 \mathrm{~mol} / \mathrm{d}$ ) considerably exceeded the amount of $\mathrm{Cl}$ flowing at the reticulum. It appears, therefore, that appreciable absorption of $\mathrm{Cl}$ occurred from the reticulo-rumen although $\mathrm{Cl}$ concentration in that organ (Table 2) was only about one-tenth of that in plasma. Indeed, it is well established that $\mathrm{Cl}$ may be actively absorbed from the reticulo-rumen against an electrochemical gradient although not all workers have concluded that appreciable net transfer of $\mathrm{Cl}$ occurs in practice (Keynes \& Harrison, 1970). Such an apparent lack of uptake may sometimes have been due to a failure to take account of exchange in the omasum. In the present work it was apparent that much of the $\mathrm{Cl}$ absorbed from the reticulo-rumen was added back during passage of digesta through the omasum; a change that was probably associated with the absorption of bicarbonate as has been shown to occur in the sheep (Engelhardt \& Hauffe, 1975).

It is likely that the differences in $\mathrm{pH}$ of digesta between rumen and reticulum were due mainly to a lag in achieving complete mixing of saliva entering the reticulum. However, the slight but consistent fall in $\mathrm{pH}$ during passage through the omasum was presumably related to ion exchange across the omasal wall including the replacement of bicarbonate by $\mathrm{Cl}$ as the major anion. Neither of these differences was, however, substantial and the results confirm earlier observations (Prins et al. 1972) indicating the maintenance of essentially constant $\mathrm{pH}$ conditions during passage of digesta through the omasum.

Together the present results provide information on the marked local fluctuations in the ionic environment as digesta pass from one stomach compartment to another. In the calf it is apparent that the omasum plays a central role in recovering minerals and water added to the reticulo-rumen and in cushioning the dramatic change in digesta composition between this organ and the abomasum.

\section{REFERENCES}

Ash, R. W. (1962). Journal of Physiology 164, 25 P.

Bertoni, G., Watson, M. J., Savage, G. P. \& Armstrong, D. G. (1976). Zootecnica e Nutrizione Animale 2, $107-118$. Brüggemann, J., Walser-Kärst, K. \& Giesecke, D. (1965). Zeitschrift für Tierphysiologie, Tierernährung und Futtermittelkunde 20, 295-305.

Dobson, A., Sellers, A. F. \& Gatewood, V. H. (1976). American Journal of Physiology 231, $1588-1594$.

Durand, M. \& Kawashima, R. (1980). In Digestive Physiology and Metabolism in Ruminants, pp. 375-408 [Y. Ruckebusch and P. Thivend, editors]. Lancaster: MTP Press Ltd.

Edrise, B. M. (1979). Exchanges of certain constituents during passage of digesta through the stomach compartments of the ruminating bovine. PhD Thesis, University of Reading.

Edrise, B. M. \& Smith, R. H. (1979). Annales de Recherches Vétérinaires 10, 354-355.

Edrise, B. M., Smith, R. H. \& Buttle, B. L. (1977). Proceedings of the Nutrition Society 36, 8 A.

Engelhardt, W. v. \& Hauffe, R. (1975). In Digestion and Metabolism in the Ruminant, pp. 216-230[I. W. McDonald and A. C. I. Warner, editors]. Armidale: University of New England Publishing Unit.

Ferreira, H. G., Harrison, F. A., Keynes, R. D. \& Zurich, L. (1972). Journal of Physiology 222, 77-93.

Hauffe, R. \& Engelhardt, W. v. (1975). Zentralblatt für Veterinärmedizin A 22, 149-163.

Horn, J. P. \& Smith, R. H. (1978). British Journal of Nutrition 40, 473-484.

Kay, R. N. B. (1960). Journal of Physiology 150, 515-537.

Keynes, R. D. \& Harrison, F. A. (1970). In Physiology of Digestion and Metabolism in the Ruminant, pp. 113-118 [A. T. Phillipson, editor]. Newcastle upon Tyne: Oriel Press Ltd.

Ministry of Agriculture, Fisheries and Food (1975). Energy Allowances and Feeding Systems for Ruminants. Technical Bulletin no. 33. London: H.M. Stationery Office.

Oyaert, W. \& Bouchaert, J. H. (1961). Research in Veterinary Science 2, 41-52.

Prins, R. A., Hungate, R. E. \& Prast, E. R. (1972). Comparative Biochemistry and Physiology 43, $155-163$.

Scott, D. (1967). Quarterly Journal of Experimental Physiology 52, 382-391. 
Scott, D. (1975). In Digestion and Metabolism in the Ruminant, pp. 205-215 [I. W. McDonald and A. C. I. Warner, editors]. Armidale: University of New England Publishing Unit.

Sellers, A. F. \& Dobson, A. (1960). Research in Veterinary Science 1, 95-102.

Sellers, A. F. \& Stevens, C. E. (1966). Physiological Reviews 46, 634-661.

Smith, R. H. (1958). Nature 182, 260-261.

Smith, R. H. (1984). Proceedings of the Nutrition Society 43, 63-68.

Tan, T. N., Weston, R. H. \& Hogan, J. P. (1971). International Journal of Applied Radiation and Isotopes 22, 301-308.

Yang, M. G. \& Thomas, J. W. (1965). Journal of Nutrition 87, 444-458.

Yarns, D. A., Putnam, P. A. \& Leffel, E. C. (1965). Journal of Animal Science 24, 173-176. 